\title{
Review \\ Emerging Links between Microbiome Composition and Skin Immunology in Diaper Dermatitis: A Narrative Review
}

\author{
Tjaša Hertiš Petek ${ }^{1,2, *(D)}$, Maya Petek ${ }^{2}(D)$, Tadej Petek ${ }^{1,2}(\mathbb{D})$ and Nataša Marčun Varda ${ }^{1,2}(\mathbb{D})$ \\ 1 Department of Pediatrics, University Medical Center Maribor, 2000 Maribor, Slovenia; \\ tadej.petek@ukc-mb.si (T.P.); natasa.marcunvarda@ukc-mb.si (N.M.V.) \\ 2 Faculty of Medicine, University of Maribor, 2000 Maribor, Slovenia; maya.petek@um.si \\ * Correspondence: tjasa.hertispetek@ukc-mb.si; Tel.: +386-(0)2-321-2110
}

Citation: Hertiš Petek, T.; Petek, M.; Petek, T;; Marčun Varda, N. Emerging Links between Microbiome Composition and Skin Immunology in Diaper Dermatitis: A Narrative Review. Children 2022, 9, 112. https://doi.org/10.3390/children 9010112

Academic Editor: Russell Hopp

Received: 8 December 2021

Accepted: 12 January 2022

Published: 15 January 2022

Publisher's Note: MDPI stays neutral with regard to jurisdictional claims in published maps and institutional affiliations.

Copyright: (c) 2022 by the authors. Licensee MDPI, Basel, Switzerland This article is an open access article distributed under the terms and conditions of the Creative Commons Attribution (CC BY) license (https:// creativecommons.org/licenses/by/ $4.0 /)$.

\begin{abstract}
Diaper dermatitis is a common type of irritant contact dermatitis occurring in infants and toddlers. Its occurrence is triggered by an unfavorable environment under the diaper, damage to skin integrity by fecal enzyme degradation, overhydration and disruption of the lipid bilayer structure facilitating the entry of irritants and microorganisms. In diaper dermatitis development, the central proinflammatory cytokines are IL- $1 \alpha$, IL- 8 and TNF- $\alpha$. The initial release of IL- $1 \alpha$ and TNF- $\alpha$ starts a further cascade of pro-inflammatory chemo- and cytokines, resulting in inflammation and erythema of the skin. A recently recognized factor in diaper dermatitis is the composition of the skin microbiome; common pathogenic strains Candida albicans and Staphylococcus aureus are associated with skin irritation. The resulting impaired microbiome composition produces a local inflammatory response and may thus worsen the initial dermatitis clinical presentation and subsequent healing. Introduction of probiotics is an attractive treatment for microbiome modulation, which has shown success in other skin conditions in adults and children. Probiotics are thought to work as a protective shield against irritants, maintain low skin $\mathrm{pH}$, secrete beneficial metabolites, and block pathogen invasion. There is preliminary evidence that certain probiotics given orally or topically could be used as a gentle intervention in diaper dermatitis.
\end{abstract}

Keywords: diaper dermatitis; immunology; inflammation; microbiome; nappy rash; pediatrics; $\mathrm{pH}$; probiotics; skin

\section{Introduction}

Diaper dermatitis (DD), also known as diaper/napkin/nappy rash, encompasses various infant dermatoses occurring in the perineal and perianal area [1]. These eruptions may represent exacerbations of diffuse skin diseases, such as seborrheic dermatitis or atopic dermatitis (AD), or skin conditions that coincidently manifest in the diaper covered area [2]. This review uses the stricter definition, where DD is defined as a type of irritant contact dermatitis (ICD), occurring mostly in reaction to prolonged contact with urine, feces, or retained soaps and detergents (falling under the ICD10 diaper dermatitis L22 diagnosis), resulting in an acute inflammatory skin process [3].

As one of the most prevalent skin conditions affecting babies, DD presents a problem to many parents after the birth of their child [4]. It usually occurs in the first two years of life, especially between 9 and 12 months of age [5,6]. A recent study estimated the prevalence of DD in children under the age of 2 at around 36\%, which decreased significantly with increasing age [7]. DD typically affects the lower abdomen, thighs, and the entire area under the diaper, including intertriginous folds. DD initially presents with desiccation of the skin, followed by development of erythematous maceration and oedema [3].

Few studies so far have addressed the specific mechanism of skin inflammation in diaper dermatitis [8-11]. While research on the skin microbiome in the diaper microenvironment has already been reviewed [12], evidence is lacking on the interplay between 
inflammatory processes and the corresponding microbiome in the diaper area. Here, we review the literature on the skin microbiome composition and inflammatory processes in children with diaper dermatitis, focusing on whether reversal of inflammation via alteration of the diaper skin microbiome might be achieved.

\section{Methods and Materials}

A PubMed, MEDLINE, CINAHL, Cochrane Library and Google Scholar search was conducted independently by two investigators (T.H.P., T.P.) for search terms "diaper dermatitis", "napkin rash", "nappy rash", "eczema", "atopic dermatitis", "irritant contact dermatitis", "incontinence associated dermatitis", "skin", "probiotics", "pediatrics", "inflammation", "inflammatory process", " $\mathrm{pH}^{\prime}$, "microbiota", and "microbiome". A manual search of relevant reference lists was also performed.

For this narrative critical review, original research and review articles in English and Slovene languages reporting results in children and adults were included. There was no limit on the publication date, although we aimed to include studies within the last 20 years. Any discrepancies regarding the inclusion of a study were discussed with another investigator (M.P.) and resolved.

The included studies were further assessed for the quality of the design and of the results presented. No standardized study assessment tools were used. If applicable, the potential bias of an industry-sponsored study was evaluated and discussed in the manuscript text. Both positive and negative studies were included. Due to the small number of pediatric studies on inflammation, dermal microbiome and probiotics use in diaper dermatitis, applicable studies on other types of dermatitis in children and adults were also included in the second stage of literature acquisition.

\section{Results}

\subsection{Early Fetal and Postnatal Microbiome}

Adult skin is mainly colonized by four different phyla with quite stable dominant genera: Actinobacteria (most dominant reported genera: Propionibacterium and Corynebacterium), Firmicutes (most represented by Lactobacillus, Streptococcus and Staphylococcus), Proteobacteria and Bacteroidetes, respectively [13].

Dermal bacterial colonization is generally thought to begin at birth and continues forming throughout the first years of life and into adulthood [14,15]. The mode of fetal delivery is recognized as the major determinant of the newborn's cutaneous microbiome composition [15]. Recently, some authors proposed that maternal microbiota is selectively transported to the placenta to colonize the fetus already before birth. This was supported by reports of bacterial DNA in the placenta and amnion [16]. The presence of oral and meconium microbiota has been reported at the time of Caesarean delivery, supposedly originating from the placenta [17]. It appears this early lack of sterility may be protective. Non-sterile meconium-stained amniotic fluid is present in $5 \%$ to $20 \%$ of deliveries and was reported to reduce the risk of developing dermatitis and decreased skin-eruption-related hospitalizations throughout childhood and adolescence [18].

Immediately after birth, infant skin bacterial communities have been reported to be similar across body sites [19]. As soon as two days after delivery, bacterial communities begin to diverge into distinct functional communities at different skin sites, which are similar to those found in adults [20]. The buttock skin bacteria soon form a separate microbiome environment, due to less likely competition from other skin sites to the diaper covered area and proximity to the gastrointestinal tract [21]. Commonly isolated bacteria from the diaper area of neonates less than a week old are species of Bifidobacteria and Bacteroides, followed by Enterobacteria, Eubacteria, Lactobacilli, amongst others [12,22].

Site-specific evolution of different bacterial communities appears to happen within the first three months of life [21]. Six weeks after delivery, the skin microbiota of mother and infant are more similar than their microbiota at other body sites, like the gut and oropharynx, which diverge more rapidly [23]. Over the first year of life the similarity between mother 
and infant microbiota further decreases as successful invasion of the environmental strains becomes more important [24]. In time, the infant's own gastrointestinal flora becomes an important contributor to the microbiota under the diaper, mainly colonized with Clostridium species (spp.) and other gut-derived bacteria, and also significant amounts of Bacteroides spp. [12].

The gastrointestinal microbiota depends on various factors, especially the child's diet: breastfed, bottle-fed or already weaned [25-27]. Numerous indicators suggest important benefits of breastfeeding for child's health during infancy and later in life [28]. Because of the oligosaccharide content, breastfeeding stimulates intestinal proliferation of anaerobic microorganisms such as species of Bifidobacteria (B. breves, B. infantis, B. pseudocatenulatum), Lactobacilli and Bacteroides. Bottle-feeding develops a mixed bacterial flora in the infant intestine, with a reduction of Bifidobacteria spp. and a greater presence of Bacteroides spp., Clostridia spp. and Staphylococci spp.. When breast-feeding is supplemented with bottle-feeding, the profile of intestinal microflora is similar to formula-fed infants [25-27]. Weaning is the main milestone when the intestinal flora becomes similar to that of an adult, with an increase in Bacteroides spp. and anaerobic gram-positive bacteria, such as Peptococci spp., Peptostreptococci spp., Veillonella spp. and Staphylococci spp. [27].

Early in life, the microbiome is highly plastic. It undergoes dynamic changes until the age of 3 to 4 years, when it stabilizes and becomes more adult-like [29]. Because of the shifting nature of microbiomes in preschool children, we believe probiotics might be especially beneficial in treating babies with DD.

\subsection{The Microbiome in Diaper Dermatitis}

The buttock area is unique in its microbiota composition with an early colonization with aerobic bacteria (Staphylococcus spp., Streptococcus spp. and Enterococcus spp.) and other transitional taxa such as Prevotella spp., Veillonella spp. and Clostridion spp.. In children with DD, the affected skin is highly susceptible to microbial infections, in particular to intestinal microbial residues [30]. In addition, both secondary bacterial and Candida infections can complicate dermatitis [3]. In DD specifically, colonization with Finegoldia [31] has been proposed as an important contributing factor because of its higher-than-expected abundance on the buttock skin area, but the mechanism is still unclear [21]. An increased presence of Enterococci, which are normal skin and gut bacteria with a pathogenic potential, has also been shown [32].

These results show that the composition of the normal skin microbiota in diaper dermatitis is altered. Bacterial diversity in DD patients is higher compared with healthy controls [30]. This contrasts the generally accepted notion of a beneficial effect of greater bacterial diversity, as seen in AD [13].

When it comes to skin flora, the DD affected area showed a paucity of beneficial strains like Staphylococcus epidermidis, Bifidobacterium longum, Clostridium butyricum and Lactobacillus ruminis [30]. Although the colonization with Staphylococcus spp. decreases with increasing DD severity, the more severe DD the predominant Staphylococcus spp. is Staphylococcus aureus, potentially implicating $S$. aureus as a DD etiological agent. In contrast, the demonstrated community percentages of fecal coliforms increase with DD severity [33]. The most often isolated pathogenic strains are Candida albicans and $S$. aureus. It is reasonable to believe that they play a predominant role in DD [12], but further research on the impact of microbiome composition on DD is certainly needed.

\subsection{Inflammation in Diaper Dermatitis}

Skin inflammation is generally triggered by external factors such as allergen intake, contact with microbes or with irritants, UV radiation and by other, less well-defined stimuli [34]. In DD skin irritation is affected by adverse fecal enzymes, friction and subsequent skin maceration, high $\mathrm{pH}$, the presence of urine and prolonged skin contact with feces [6]. Inadequate skin care, certain microbial invasion, antibiotic use and a lack of individual nutrients also play a role (Figure 1) [3]. The resulting inflammatory process involves a 
complex interplay of events between skin cells, immune cells, inflammatory cytokines, and chemokines [35].

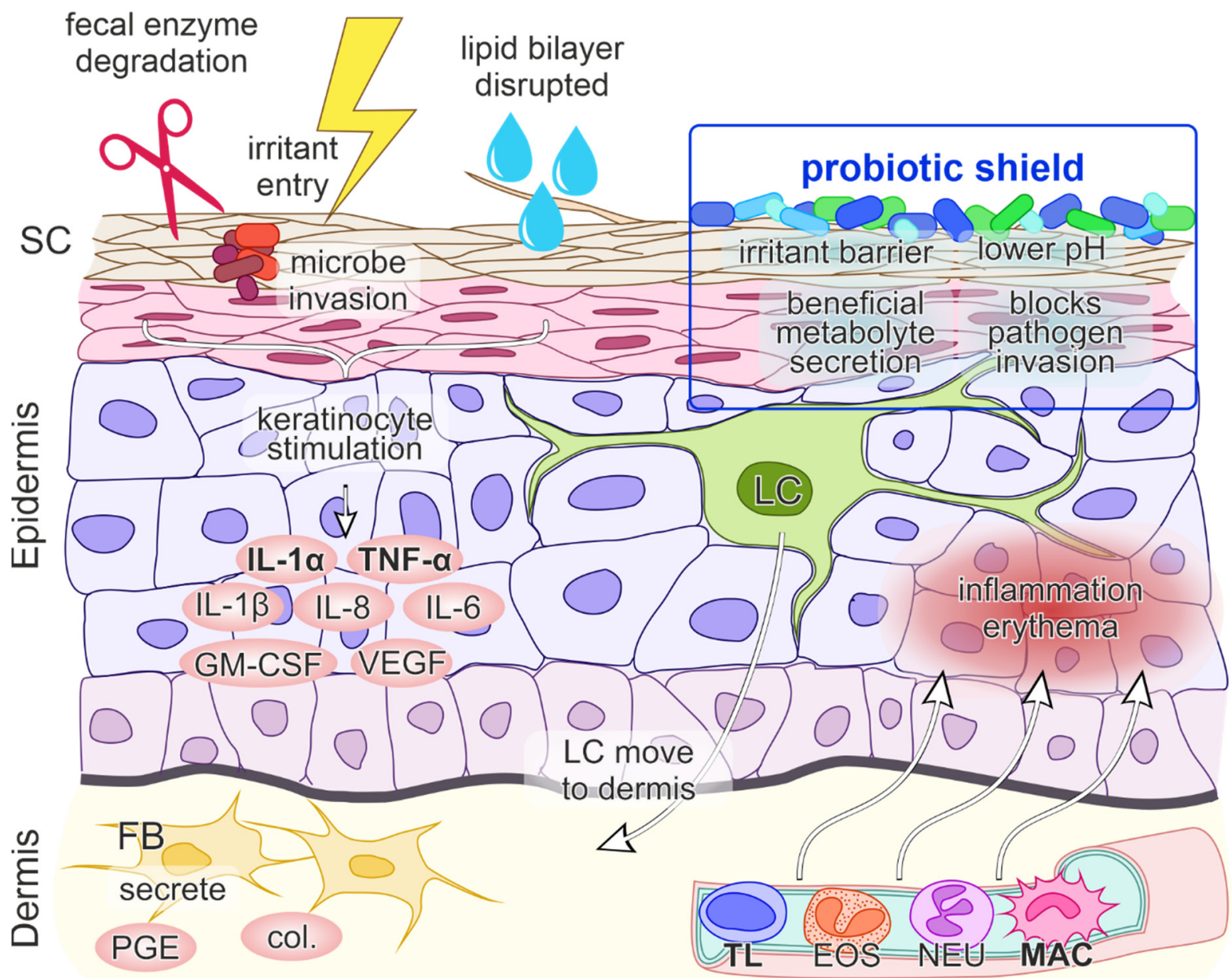

Figure 1. A model of contact irritant diaper dermatitis. The first step involves the penetration of irritants through the skin which stimulates keratinocytes $(\mathrm{KC})$ to release proinflammatory mediators interleukin 1 alpha (IL-1 $\alpha$ ) and tumor necrosis factor alpha (TNF- $\alpha$ ). The entry of irritants and microorganisms is facilitated by damage of stratum corneum (SC) integrity by fecal enzyme degradation, overhydration and disruption of the lipid bilayer structure. The initial release of IL- $1 \alpha$ and TNF- $\alpha$ promotes further production of cytokines and chemokines IL-1 $\beta$, granulocyte macrophage-colony stimulating factor (GM-CSF), IL-6, IL-8, vascular endothelial growth factor (VEGF), migration of Langerhans cells (LC) to the dermis, production of collagenases (col.) and prostaglandin E (PGE) by fibroblasts (FB), vasodilatation of the blood vessels, upregulation of adhesion molecules on endothelial cells and the transmigration of inflammatory cells (TL-T lymphocyte, EOS-eosinophil, NEU - neutrophil, MAC - macrophage) to the epidermis. The net effect is inflammation and erythema of the skin. Probiotics present a protective shield against irritants, maintain a lower $\mathrm{pH}$, secrete beneficial metabolites and block pathogen invasion.

Interleukin 1 alpha (IL- $1 \alpha)$ is a major driver of inflammation in DD, as infants with DD, heat rash and erythema show a significant increase in IL-1 $\alpha$ levels compared to healthy infants. There is a strong positive correlation between interleukin 1 receptor antagonist (IL-1RA) levels and DD severity. In the DD area authors also observed a significant increase in interleukin-8 (IL-8) levels in comparison to healthy skin sites [11]. Examination of an invitro skin model confirmed different formulae for alleviation of DD, noticing that chemical 
irritation causes a high release of IL- $1 \alpha$, impairs tissue viability as well as skin barrier integrity [10].

The importance of IL- $1 \alpha$ was further demonstrated in the first month post-partum: levels of IL-1 $\alpha$ and skin hydration were significantly increased at day 28 , while the $\mathrm{pH}$ of the skin decreased regardless of the skin care regimen. IL- $1 \alpha$ levels were significantly higher in the skin of infants wearing diapers compared to those without, while skin cleansing with care cloths or water showed no differences in microbiological colonization. Authors proposed that an increase of IL- $1 \alpha$ might reflect postnatal skin maturation [8]. In a similar study from 2014, authors described higher skin $\mathrm{pH}$, increased skin hydration and increased IL-1 $\alpha$ concentrations in infants who used diapers compared to those without [9].

\subsection{Role of Skin $p H$}

Across body sites $\mathrm{pH}$ values vary from $\mathrm{pH} 4.0$ to 7.0. Around half reports describe $\mathrm{pH}$ values below 5.0, which contrasts with the general assumption of a healthy skin $\mathrm{pH}$ being between 5.0 to 6.0. Low $\mathrm{pH}$ values below 5.0 are associated with favorable barrier function, moisturization and scaling. A proposed mechanism for low $\mathrm{pH}$ protective effect is that an acidic skin $\mathrm{pH}$ between 4.0-4.5 keeps the resident bacterial flora attached to the skin, whereas an alkaline $\mathrm{pH}$ between 8.0-9.0 promotes dispersal from the skin [36]. Maintenance of the acidic layer of the epidermis is also of major importance as it maintains a protective system of the skin and creates an unfavorable environment for colonization by pathogenic microorganisms [37]. Ammonia-induced alkalinization activates fecal enzymes such as lipase and trypsin, leading to irritation and disruption of the skin barrier. However, the skin in some cases of infants has already been reported to have an elevated baseline $\mathrm{pH}$ of 6.6 [38], suggesting a possible predisposition for DD development.

A normal $\mathrm{pH}$ value in the buttock area is around 5.5 [39] and any increase in skin $\mathrm{pH}$ in the area under the diaper promotes the growth of pathogenic microorganisms, including C. albicans and S. aureus, which seem to play a predominant role in DD [12,40,41]. The inflammatory process of the skin in the buttock area is related to specific bacterial strains that promote inflammation. For example, a characteristic of $S$. aureus infection is the formation of a neutrophilic abscess. This infection is generally characterized by inflammatory cytokines interleukin-1 beta (IL-1 $\beta)$, tumor necrotizing factor alpha (TNF- $\alpha$ ), interleukin-6 (IL-6), chemokine (CX-C motif) ligand 2 (CXCL2), and IL-8 (also known as chemokine (CX-C motif) ligand 8-CXCL8) [40]. In C. albicans infection, the cytokines IL-6, TNF- $\alpha$, interleukin-12 (IL-12), interferon- $\gamma$ (IFN- $\gamma$ ) and interleukin-17 (IL-17) appear in the initial stage of skin infection. On the other hand, anti-inflammatory cytokines interleukin-13 (IL-13), interleukin-4 (IL-4), interleukin-10 (IL-10) and transforming growth factor- $\beta$ (TGF$\beta$ ) appear on the fourth day after infection and ameliorate the exacerbation of inflammation and participate in the healing of lesions [41].

Furthermore, the humid environment leads to overhydration of the stratum corneum (SC), causing disruption of the lipid bilayer structure. When the SC integrity is damaged, irritants and microorganisms can easily penetrate and reach the epidermis and Langerhans cells. Penetrants/irritants interact with keratinocytes, stimulating the release of cytokines, which then act on dermal vasculature, resulting in inflammation (Figure 1) [42-44].

Although skin $\mathrm{pH}$, microbiome, and inflammation have been studied separately, further work is needed to elucidate connections between these factors. So far, an increase in $\mathrm{pH}$ is thought to increase the release of inflammatory biomarkers, specifically interleukins, such as IL- $1 \alpha$. It has been proposed that IL- $1 \alpha$ and TNF- $\alpha$ could serve as biomarkers of skin damage caused by urinary incontinence [45]. The question whether the increase of the skin $\mathrm{pH}$ by itself causes the inflammation or only provides suitable conditions for pathogenic colonization that afterwards causes the inflammation deserves to be further evaluated.

\subsection{Inflammatory Signaling}

At a molecular level, when DD results from a contact etiology, irritant penetration through the skin induces endogenous "danger" signals, which cause direct damage to 
keratinocytes and the release of cytokines and chemokines IL- $1 \alpha$, IL-1 $\beta$ and TNF- $\alpha$. These cytokines unsurprisingly play a central role in DD immune system activation, as they can trigger inflammation on their own. Keratinocytes additionally secrete the granulocytemacrophage colony-stimulating factor (GM-CSF), IL-6 and IL-8, where IL-8 is a potent chemokine for lymphocytes and IL-6 influences the process of maturation of keratinocytes. The initial signal release is followed by the migration of Langerhans cells to the dermis, the production of collagenases and prostaglandin $\mathrm{E}$ by fibroblasts and the upregulation of intercellular adhesion molecule 1 (ICAM-1) and vascular cell adhesion molecule 1 (VCAM-1) on keratinocytes, fibroblasts and endothelial cells. Subsequently, blood vessels dilate and passage of inflammatory cells into the epidermis ensues, leading to inflammation and erythema (Figure 1) [35,46].

Less well characterized cytokines that are involved in ICD are CCL (chemokine (C-C motif) ligand) 20, CCL27, IL-10, IL-12 and IL-18 [35]. Of these, IL-2 is the most important growth factor for $\mathrm{T}$ lymphocytes while IL-10 inhibits cytokine synthesis and thus the immune response [46]. A synergistic effect of cytokines IL-1 and TNF- $\alpha$ has been described, leading to further activation and release of secondary chemo- and cytokines such as IL-2, IL-6, GM-CSF, IFN- $\gamma$, vascular endothelial growth factor (VEGF), IL-8, CCL2, CCL5 and CCL20, which further stimulate the expression of the cellular adhesion molecules [43].

The cytokines that are primarily upregulated following irritant exposure are IL-1 $\alpha$ and TNF- $\alpha[35,43,46]$. Although the precise cytokines/chemokines activation cascade in DD is still unclear, IL-8 has also been specifically implicated as a strong contributor in DD [42].

The importance of IL- $1 \alpha$ and TNF- $\alpha$ in ICD is supported by genetic findings, showing that individuals with TNFA-308A alleles have an increased risk of ICD while those with TNFA-238A polymorphisms have a reduced risk [47]. The single nucleotide polymorphism (SNP) of IL1A-889T was also associated with less likely development of ICD [48]. SNPs involved in the development of ICD in health professionals were within the MHC Class I (OR2B3, TRIM31, TRIM10, TRIM40 and IER3), Class II (HLA-DPA1, HLA-DPB1) and Class III (C2) genes and were associated with skin response to tested irritants in different genetic models. Linkage disequilibrium patterns and functional annotations identified two SNPs in the TRIM40 (rs1573298) and HLA-DPB1 (rs9277554) genes, with a potential impact on gene regulation [49]. These results suggest that polymorphisms of individual nucleotides, associated with skin inflammation and homeostasis, can affect responses to irritants and at least partially explain individual differences in the development of contact dermatitis. IL- $1 \alpha$, IL- 8 and TNF- $\alpha$ seem to be the most important cytokines in DD [8-11,42]. Inflammatory processes depend not only on the trigger but also on genetic predispositions $[34,35]$. However, the exact cytokine profile in DD is still unknown and likely varies between patients, the microbiome composition and the irritant nature.

\subsection{Probiotics as a "Protective Shield" against Skin Inflammation}

Probiotics are live microorganisms which, when administered in adequate amounts, confer a health benefit on the host [50]. Recently the understanding of the microbiome's role in skin disease has grown, confirming that the immune system can be modulated through the introduction of specific probiotics [51].

Probiotics exert health effects on the skin directly through cutaneous formulations or indirectly through dietary supplementary formulations and intestinal microflora improvement [52]. Certain probiotics can modulate the cutaneous microflora, the lipid barrier, and the skin immune system, leading to the maintenance of skin homeostasis [53].

Beneficial dermal effects of probiotics have been shown via oral consummation through acting on the intestine with changes in systemic immune responses and thus immunomodulation of the skin, inhibition of allergen-induced tumors via changes in systemic immune responses and inhibition of harmful intestinal microflora. Probiotics can also act as antioxidant agents. Probiotics may be applied directly on the skin which then compete with harmful skin microflora, secrete useful metabolites, reduce $\mathrm{pH}$ and 
act as a barrier to harmful foreign environmental factors that are in contact with the skin (Figure 1) [52].

As the interest in the use of probiotics in DD is very recent, there is currently only very limited data available on their use as a DD prevention or treatment option. An older preliminary report from 1998 describes a trial of infant formula supplemented with Bifidobacterium lactis and Streptococcus thermophilus, which showed a small decrease in DD incidence compared to non-supplemented formula during the observation period [54]. Examining probiotics as a DD treatment, a single 2021 article reports on a market research study that followed an at-home use of oral activated Bifidobacterium infantis EVC001 in infants with DD. Parent-reported changes in DD severity, symptomatic relief of colic and sleep behaviors were collected via an online survey and showed promising outcomes: $72 \%(n=448)$ of the participants whose infants had ever experienced diaper rash reported improvements, and $57 \%$ of those reported complete resolution of diaper rash [55]. Although the consumer feedback was very positive, this type of research presents substantial methodological limitations; there is little opportunity to monitor confounding factors and possible bias incentives. Further, more rigorous scientific research on use of probiotics in $\mathrm{DD}$ is desired.

In children the evidence for probiotics use exists mainly for AD [27], for which a recent systematic review on use of probiotics in $\mathrm{AD}$ concluded that certain probiotic preparations were efficient in reducing risk of developing $\mathrm{AD}$ when administered to pregnant women, infants, or both [56]. A number of probiotic preparations showed an effect: a mix of Lactobacillus paracasei ST11 and Bifidobacterium longum BL999; the L. paracasei ssp. paracasei strain F19; L. rhamnosus GG with B. animalis ssp. lactis BB-12 [56]. An older review study concluded that L. rhamnosus GG and B. lactis BB-12 showed an effect when adjunct to extensively hydrolyzed formula in treating infants with mild AD and cow's milk allergy, and the combination of L. rhamnosus 19070-2 and L. reuteri DSM 122460 was effective in patients with moderate to severe AD [27].

Although the skin barrier is altered in both $\mathrm{AD}$ and $\mathrm{DD}$, the pathogenic mechanism differs between the two types of dermatitis. In searching for evidence of probiotics use in childhood dermatitis, we searched for studies in ICD (which would be the most relevant), but no results were found. Instead, the closest relevant results were found for eczema in general, not specifying whether atopic, contact, dyshidrotic, seborrheic etc. In eczema, the evidence is mixed: Lactobacillus and Bifidobacterium strains showed a protective effect, although Bifidobacterium was not tested unilaterally [57]. In contrast, a recent systematic review concluded that currently available probiotic strains probably make little or no difference in improving patient-rated eczema symptoms. Results show significant, unexplainable heterogeneity between individual trial results. The authors suggest that in the future, researchers should also consider studying subgroups of patients (e.g., patients with atopy or food allergies, adults) and standardize the doses/concentrations of probiotics given [58]. In summary, the heterogeneity of terms and definitions regarding eczema is the major limitation of studies that reported effect of probiotics on the skin, limiting the possibility of generalization [57]. The current consensus recommendation of the International Eczema Council (IEC) is to use of the prefix "atopic" (i.e., AD or AE) in all publications, presentations and discussions about the disorder [59]. We expect that the quality of the available evidence will improve with more precise reporting of the treated skin pathology.

Finally, due to limited reports on probiotic interventions for dermatitis in children, we expanded our search to include relevant studies in adult populations. Positive results for probiotic interventions in adults were reported for acne vulgaris, psoriasis, diabetes skin ulcers, acute and chronic wounds, skin cancers, burns, seborrheic dermatitis, photoaging and allergic contact dermatitis [51,60]. Most studies investigated oral probiotic interventions, and of those utilizing topical probiotics, few included skin commensals [51]. Some authors also present positive clinical findings on gut-skin axis interventions with oral probiotics [61,62]. Although we searched extensively for the use of probiotics in ICD 
or incontinence associated dermatitis in adults, which would be most applicable for DD in children, there were no studies reported.

However, there are some adult studies that tested the effect of probiotics on skin barrier function. In one trial, participants were consuming L. brevis SBC8803 oral supplements for 3 months, which resulted in decreased transepidermal water loss (TEWL) and increased corneal hydration [63]. In a placebo-controlled human study, bacterial supplementation had a positive effect on skin barrier function. When participants were taking L. paracasei NCC2461 supplements for 8 weeks, they developed decreased skin sensitivity and TEWL. Circulating TGF- $\beta$ levels, a cytokine that is beneficial for a barrier integrity, were increased after the use of probiotics [64].

Even though studies on the skin barrier function examined the effects of probiotics on undiapered adult skin, the results might be relevant to DD as the formation of ICD in DD is closely related to the maintenance of skin barrier integrity. Still, DD specific trials are certainly needed because the generalizability is limited by factors including different study populations (adult vs. infant) and skin environment effects (diaper coverage).

\section{Conclusions and Outlook}

Although the immediate cause of DD is contact with environmental irritants, the individual predispositions to its development and severity are less clear. The microbiome composition seems to be an important factor. Evidence for microbiota modulation with probiotics in children exists mainly for atopic dermatitis (AD), where some studies reported positive results [27].

The exact pathophysiological mechanism of probiotic immune system modulatory effects and counteraction of inflammation processes in DD is yet to be understood. IL- $1 \alpha$, $\mathrm{TNF} \alpha$ and IL-8 seem to play a central role in driving DD inflammation, but exact involvement of other cytokines and chemokines is still to be uncovered. Furthermore, the interplay of inflammatory pathway activation and the microbiome require further investigation.

When it comes to diaper rash, Zheng and colleagues recently reported that altered skin microflora indicates imbalance and dynamism of microbiome in diaper rash. They were one of the first to suggest that the use of probiotics could be potentially a successful strategy for the prevention and treatment of diaper rash [30]. The use of probiotics in DD is a promising research direction, as probiotic intervention clinical trials have yielded positive results in various skin conditions in adults and children.

We believe that probiotics are a promising, gentle intervention for children with DD, and their use warrants further exploration. Such trials should be supported by additional research into greater understanding of the correlation between inflammation and microbiome in DD.

Author Contributions: All authors made substantial contributions to the design, analysis and writing of this work, and approve the submitted version. The contributions were: Conceptualization, T.H.P. and N.M.V., Methodology, T.H.P., Investigation, T.H.P., M.P. and T.P., Writing-Original Draft Preparation, T.H.P., Writing-Review and Editing, T.H.P., M.P., T.P. and N.M.V., Visualization, M.P. and T.H.P., Supervision and Funding Acquisition, N.M.V. All authors have read and agreed to the published version of the manuscript.

Funding: This work was completed as a part of a project by the Slovenian Research Agency (grant number: J3-1762).

Institutional Review Board Statement: The review was carried out in a qualified institution and was conducted in accordance with the provisions of the Declaration of Helsinki, the Oviedo Convention, and the principles of the Slovenian Code of Medical Deontology.

Informed Consent Statement: Not applicable.

Data Availability Statement: All the data are available within the manuscript.

Conflicts of Interest: The authors have no conflicts of interest to declare. 


\section{References}

1. Benitez Ojeda, A.B.; Mendez, M.D. Diaper Dermatitis. In StatPearls Publishing. Updated 21 July 2021. Available online: https:/ / www.ncbi.nlm.nih.gov/books/NBK559067/ (accessed on 13 January 2021).

2. Klunk, C.; Domingues, E.; Wiss, K. An update on diaper dermatitis. Clin. Dermatol. 2014, 32, 477-487. [CrossRef]

3. Tüzün, Y.; Wolf, R.; Bağlam, S.; Engin, B. Diaper (napkin) dermatitis: A fold (intertriginous) dermatosis. Clin. Dermatol. 2015, 33, 477-482. [CrossRef] [PubMed]

4. Blume-Peytavi, U.; Kanti, V. Prevention and treatment of diaper dermatitis. Pediatr. Dermatol. 2018, 35, s19-s23. [CrossRef] [PubMed]

5. Cohen, B. Differential diagnosis of diaper dermatitis. Clin. Pediatr. 2017, 56 (Suppl. 5), 16S-22S. [CrossRef] [PubMed]

6. $\quad$ Atherton, D.J. Understanding irritant napkin dermatitis. Int. J. Dermatol. 2016, 55 (Suppl. 1), 7-9. [CrossRef]

7. Sukhneewat, C.; Chaiyarit, J.; Techasatian, L. Diaper dermatitis: A survey of risk factors in Thai children aged under 24 months. BMC Dermatol. 2019, 19, 7. [CrossRef] [PubMed]

8. Garcia Bartels, N.; Massoudy, L.; Scheufele, R.; Dietz, E.; Proquitté, H.; Wauer, R.; Bertin, C.; Serrano, J.; Blume-Peytavi, U. Standardized diaper care regimen: A prospective, randomized pilot study on skin barrier function and epidermal IL-1 $\alpha$ in newborns. Pediatr. Dermatol. 2012, 29, 270-276. [CrossRef]

9. Garcia Bartels, N.; Lünnemann, L.; Stroux, A.; Kottner, J.; Serrano, J.; Blume-Peytavi, U. Effect of diaper cream and wet wipes on skin barrier properties in infants: A prospective randomized controlled trial. Pediatr. Dermatol. 2014, 31, 683-691. [CrossRef]

10. Zhuang, L.; Gu, H.; Huang, Y.; Li, X.; Lu, Y.; Kaku, K. Development of a new diaper dermatitis-like reconstructed skin equivalent for testing children atopic dermatitis relieving cosmetics. Skin Res. Technol. 2019, 25, 839-845. [CrossRef]

11. Perkins, M.A.; Osterhues, M.A.; Farage, M.A.; Robinson, M.K. A noninvasive method to assess skin irritation and compromised skin conditions using simple tape adsorption of molecular markers of inflammation. Skin Res. Technol. 2001, 7, 227-237. [CrossRef]

12. Šikić Pogačar, M.; Maver, U.; Marčun Varda, N.; Mičetić-Turk, D. Diagnosis and management of diaper dermatitis in infants with emphasis on skin microbiota in the diaper area. Int. J. Dermatol. 2018, 57, 265-275. [CrossRef]

13. Schommer, N.N.; Gallo, R.L. Structure and function of the human skin microbiome. Trends Microbiol. 2013, 21, 660-668. [CrossRef] [PubMed]

14. Schneider, A.M.; Nelson, A.M. Skin microbiota: Friend or foe in pediatric skin health and skin disease. Pediatr. Dermatol. 2019, 36, 815-822. [CrossRef] [PubMed]

15. Schoch, J.J.; Monir, R.L.; Satcher, K.G.; Harris, J.; Triplett, E.; Neu, J. The infantile cutaneous microbiome: A review. Pediatr. Dermatol. 2019, 36, 574-580. [CrossRef] [PubMed]

16. Casterline, B.W.; Paller, A.S. Early development of the skin microbiome: Therapeutic opportunities. Pediatr. Res. 2021, 90, 731-737. [CrossRef]

17. Younge, N.; McCann, J.R.; Ballard, J.; Plunkett, C.; Akhtar, S.; Araújo-Pérez, F.; Murtha, A.; Brandon, D.; Seed, P.C. Fetal exposure to the maternal microbiota in humans and mice. JCI Insight 2019, 4, e127806. [CrossRef]

18. Krieger, Y.; Horev, A.; Wainstock, T.; Sheiner, E.; Walfisch, A. Meconium-stained amniotic fluid as a protective factor against childhood dermatitis and skin rash-related hospitalization in the offspring-A population-based cohort analysis. J. Eur. Acad Dermatol. Venereol. 2020, 34, 319-324. [CrossRef]

19. Dominguez-Bello, M.G.; Costello, E.K.; Contreras, M.; Magris, M.; Hidalgo, G.; Fierer, N.; Knight, R. Delivery mode shapes the acquisition and structure of the initial microbiota across multiple body habitats in newborns. Proc. Natl. Acad. Sci. USA 2010, 107, 11971-11975. [CrossRef]

20. Kennedy, E.A.; Connolly, J.; Hourihane, J.O.; Fallon, P.; McLean, W.I.; Murray, D.; Jo, J.-H.; Segre, J.A.; Kong, H.H.; Irvine, A.D. Skin microbiome before development of atopic dermatitis: Early colonization with commensal staphylococci at 2 months is associated with a lower risk of atopic dermatitis at 1 year. J. Allergy Clin. Immunol. 2017, 139, 166-172. [CrossRef] [PubMed]

21. Capone, K.A.; Dowd, S.E.; Stamatas, G.N.; Nikolovski, J. Diversity of the human skin microbiome early in life. J. Investig. Dermatol. 2011, 131, 2026-2032. [CrossRef] [PubMed]

22. Grice, E.A.; Segre, J.A. The skin microbiome. Nat. Rev. Microbiol. 2011, 9, 244-253. [CrossRef]

23. Chu, D.M.; Ma, J.; Prince, A.L.; Antony, K.M.; Seferovic, M.D.; Aagaard, K.M. Maturation of the infant microbiome community structure and function across multiple body sites and in relation to mode of delivery. Nat. Med. 2017, 23, 314-326. [CrossRef]

24. Gaitanis, G.; Tsiouri, G.; Spyridonos, P.; Stefos, T.; Stamatas, G.N.; Velegraki, A.; Bassukas, I.D. Variation of cultured skin microbiota in mothers and their infants during the first year postpartum. Pediatr. Dermatol. 2019, 36, 460-465. [CrossRef]

25. Mattila-Sandholm, T.; Blum, S. Probiotics: Towards demonstrating efficacy. Trends Food Sci. Technol. 1999, 10, 393-399. [CrossRef]

26. Harmsen, H.J.M.; Wildeboer-Veloo, A.C.M.; Raangs, G.C.; Wagendorp, A.A.; Klijn, N.; Bindels, J.G.; Welling, G.W. Analysis of intestinal flora development in breast-fed and formula-fed infants by using molecular identification and detection methods. $J$. Pediatr. Gastroenterol. Nutr. 2000, 30, 61-67. [CrossRef] [PubMed]

27. Caramia, G.; Atzei, A.; Fanos, V. Probiotics and the skin. Clin. Dermatol. 2008, 26, 4-11. [CrossRef]

28. Mičetić Turk, D.; Turk, E.; Šikić Pogačar, M. Historical overview of breastfeeding in Slovenia. Acta Med.-Biotech. 2017, 10, 18-24.

29. Kumbhare, S.V.; Patangia, D.V.; Patil, R.H.; Shouche, Y.S.; Patil, N.P. Factors influencing the gut microbiome in children: From infancy to childhood. J. Biosci. 2019, 44, 49. [CrossRef] [PubMed] 
30. Zheng, Y.; Wang, Q.; Ma, L.; Chen, Y.; Gao, Y.; Zhang, G.; Cui, S.; Liang, H.; Song, L.; He, C. Shifts in the skin microbiome associated with diaper dermatitis and emollient treatment amongst infants and toddlers in China. Exp. Dermatol. 2019, 28, 1289-1297. [CrossRef]

31. Goto, T.; Yamashita, A.; Hirakawa, H.; Matsutani, M.; Todo, K.; Ohshima, K.; Toh, H.; Miyamoto, K.; Kuhara, S.; Hattori, M.; et al Complete genome sequence of Finegoldia magna, an anaerobic opportunistic pathogen. DNA Res. 2008, 15, 39-47. [CrossRef]

32. Ferrazzini, G.; Kaiser, R.R.; Hirsig Cheng, S.-K.; Wehrli, M.; Della Casa, V.; Pohlig, G.; Gonser, S.; Graf, F.; Jörg, W. Microbiological aspects of diaper dermatitis. Dermatology 2003, 206, 136-141. [CrossRef]

33. Teufel, A.; Howard, B.; Hu, P.; Carr, A.N. Characterization of the microbiome in the infant diapered area: Insights from healthy and damaged skin. Exp. Dermatol. 2021, 30, 1409-1417. [CrossRef] [PubMed]

34. Bäsler, K.; Brandner, J.M. Tight junctions in skin inflammation. Pflugers Arch. Eur. J. Physiol. 2017, 469, 3-14. [CrossRef] [PubMed]

35. Ho, K.K.; Campbell, K.L.; Lavergne, S.N. Contact dermatitis: A comparative and translational review of the literature. Vet. Dermatol. 2015, 26, 314-e67. [CrossRef] [PubMed]

36. Lambers, H.; Piessens, S.; Bloem, A.; Pronk, H.; Finkel, P. Natural skin surface pH is on average below 5, which is beneficial for its resident flora. Int. J. Cosmet. Sci. 2006, 28, 359-370. [CrossRef]

37. Rippke, F.; Berardesca, E.; Weber, T.M. pH and microbial infections. Curr. Probl. Dermatol. 2018, 54, 87-94. [PubMed]

38. Schmid-Wendtner, M.-H.; Korting, H.C. The $\mathrm{pH}$ of the skin surface and its impact on the barrier function. Skin Pharmacol. Physiol. 2006, 19, 296-302. [CrossRef]

39. Hoeger, P.H.; Enzmann, C.C. Skin physiology of the neonate and young infant: A prospective study of functional skin parameters during early infancy. Pediatr. Dermatol. 2002, 19, 256-262. [CrossRef] [PubMed]

40. Miller, L.S.; Cho, J.S. Immunity against Staphylococcus aureus cutaneous infections. Nat. Rev. Immunol. 2011, 11, 505-518. [CrossRef]

41. Campois, T.; Zucoloto, A.Z.; Araujo, E.J.D.A.; Svidizinski, T.I.E.; Almeida, R.S.; Quirino, G.F.D.S.; Harano, R.M.; Conchon-Costa, I.; Felipe, I. Immunological and histopathological characterization of cutaneous candidiasis. J. Med. Microbiol. 2015, 64, 810-817. [CrossRef]

42. Visscher, M.O. Recent advances in diaper dermatitis: Etiology and treatment. Pediatr. Health 2009, 3, 81-98. [CrossRef]

43. Lee, H.Y.; Stieger, M.; Yawalkar, N.; Kakeda, M. Cytokines and chemokines in irritant contact dermatitis. Mediat. Inflamm. 2013, 2013, 916497. [CrossRef]

44. Nosbaum, A.; Vocanson, M.; Rozieres, A.; Hennino, A.; Nicolas, J.F. Allergic and irritant contact dermatitis. Eur. J. Dermatol. 2009, 19, 325-332. [CrossRef]

45. Koudounas, S. Investigation of the Underlying Mechanisms Leading to the Development of Incontinence-Associated Dermatitis. Ph.D. Thesis, University of Southampton, Southampton, UK, 2019. Available online: http:/ / eprints.soton.ac.uk/id/eprint/433262 (accessed on 10 January 2022).

46. Gosenca, M.; Gašperlin, M.; Kristl, J. Irritative contact dermatitis: From mechanism of irritation to irritants' assessment. Farm. Vestn. 2012, 63, 145-152.

47. Landeck, L.; Visser, M.; Kezic, S.; John, S.M. Impact of tumour necrosis factor- $\alpha$ polymorphisms on irritant contact dermatitis. Contact Derm. 2012, 66, 221-227. [CrossRef] [PubMed]

48. Landeck, L.; Visser, M.; Kezic, S.; John, S.M. IL1A-889 C/T gene polymorphism in irritant contact dermatitis. J. Eur. Acad Dermatol. Venereol. 2013, 27, 1040-1043. [CrossRef] [PubMed]

49. Yucesoy, B.; Talzhanov, Y.; Barmada, M.M.; Johnson, V.J.; Kashon, M.L.; Baron, E.; Wilson, N.W.; Frye, B.; Wang, W.; Fluharty, K.; et al. Genetic basis of irritant susceptibility in health care workers. J. Occup. Environ. Med. 2016, 58, 753-759. [CrossRef] [PubMed]

50. Joint FAO/WHO Working Group. Guidelines for the Evaluation of Probiotics in Food; Food and Agriculture Organization of the United Nations, WHO: London, ON, Canada, 2002.

51. Yu, Y.; Dunaway, S.; Champer, J.; Kim, J.; Alikhan, A. Changing our microbiome: Probiotics in dermatology. Br. J. Dermatol. 2020, 182, 39-46. [CrossRef]

52. Roudsari, M.R.; Karimi, R.; Sohrabvandi, S.; Mortazavian, A.M. Health effects of probiotics on the skin. Crit. Rev. Food Sci. Nutr. 2015, 55, 1219-1240. [CrossRef]

53. Cinque, B.; La Torre, C.; Melchiorre, E.; Marchesani, G.; Zoccali, G.; Palumbo, P.; Di Marzio, L.; Masci, A.; Mosca, L.; Mastromarino, P.; et al. Use of probiotics for dermal applications. Probiotics 2011, 21, 221-241.

54. Saavedra, J.; Abi-Hanna, A.; Moore, N.; Yolken, R. Effect of long term consumption of infant formulas with Bifidobacteria (B) and S. thermophilus (ST) on stool patterns and diaper rash in infants. J. Pediatr. Gastroenterol. Nutr. 1998, 27, 483. [CrossRef]

55. Dimitratos, S.M.; Brown, H.; Shafizadeh, T.; Kazi, S.; Altmann, T.; Ostrer, B. Symptomatic relief from at-home use of activated Bifidobacterium infantis EVC001 probiotic in infants: Results from a consumer survey on the effects on diaper rash, colic symptoms, and sleep. Benef. Microbes 2021, 12, 333-340. [CrossRef] [PubMed]

56. Tan-Lim, C.S.C.; Esteban-Ipac, N.A.R.; Recto, M.S.T.; Castor, M.A.R.; Casis-Hao, R.J.; Nano, A.L.M. Comparative effectiveness of probiotic strains on the prevention of pediatric atopic dermatitis: A systematic review and network meta-analysis. Pediatr. Allergy Immunol. 2021, 32, 1255-1270. [CrossRef]

57. Mansfield, J.A.; Bergin, S.W.; Cooper, J.R.; Olsen, C.H. Comparative probiotic strain efficacy in the prevention of eczema in infants and children: A systematic review and meta-analysis. Mil. Med. 2014, 179, 580-592. [CrossRef] 
58. Boyle, R.J.; Bath-Hextall, F.J.; Leonardi-Bee, J.; Murrell, D.F.; Tang, M.L. Probiotics for treating eczema. Cochrane Database Syst. Rev. 2018, 11. [CrossRef]

59. Silverberg, J.I.; Thyssen, J.P.; Paller, A.S.; Drucker, A.M.; Wollenberg, A.; Lee, K.H.; Kabashima, K.; Todd, G.; Schmid-Grendelmeier, P.; Bieber, T. What's in a name? Atopic dermatitis or atopic eczema, but not eczema alone. Allergy 2017, 72, 2026-2030. [CrossRef] [PubMed]

60. Lolou, V.; Panayiotidis, M.I. Functional role of probiotics and prebiotics on skin health and disease. Fermentation $2019,5,41$. [CrossRef]

61. Salem, I.; Ramser, A.; Isham, N.; Ghannoum, M.A. The gut microbiome as a major regulator of the gut-skin axis. Front. Microbiol. 2018, 9, 1459. [CrossRef]

62. O'Neill, C.A.; Monteleone, G.; McLaughlin, J.T.; Paus, R. The gut-skin axis in health and disease: A paradigm with therapeutic implications. Bioessays 2016, 38, 1167-1176. [CrossRef] [PubMed]

63. Ogawa, M.; Saiki, A.; Matsui, Y.; Tsuchimoto, N.; Nakakita, Y.; Takata, Y.; Nakamura, T. Effects of oral intake of heat-killed Lactobacillus brevis SBC8803 (SBL88TM) on dry skin conditions: A randomized, double-blind, placebo-controlled study. Exp. Ther. Med. 2016, 12, 3863. [CrossRef] [PubMed]

64. Gueniche, A.; Philippe, D.; Bastien, P.; Reuteler, G.; Blum, S.; Castiel-Higounenc, I.; Breton, L.; Benyacoub, J. Randomised double-blind placebo-controlled study of the effect of Lactobacillus paracasei NCC 2461 on skin reactivity. Benef. Microbes 2014, 5, 137-145. [CrossRef] [PubMed] 